\title{
Teaching methods in Physiology: Students' Feedback
}

\author{
Dr RautSayali $E^{1}$, Dr PagarAtish $\mathrm{B}^{1}$, Dr.Kadam Charulata ${ }^{1}$ Dr KowaleArun $\mathrm{N}^{2}$, \\ Dr Bhutada Tara $\mathrm{B}^{1}$,Dr.Aundhkar V. $\mathrm{G}^{1}$, \\ ${ }^{1}$ (Department of Physiology, GMC Miraj, Maharashtra, India) \\ ${ }^{2}$ (Department of Physiology, B J Medical College Pune, Maharashtra, India)
}

\begin{abstract}
BACKGROUND: The mainstream of tertiary education has seen a massive transformation over the last few decades and the move towards student centered learning is finding support in the physiological sciences. It is becoming increasingly urgent to find ways of evaluating teaching/learning strategies. So, there is a need for educational research and on-going evaluation must be considered to be a fundamental part of educational advance.OBJECTIVE: To evaluate the different teaching methods practiced in Physiology using students' feedback. MATERIAL AND METHODS: Based on the teaching methods practiced in the department of Physiology, a questionnaire paper was given to 200 medical students of $3^{\text {rd }}(I I / I) \& 5^{\text {th }}$ (II/III) semester to be answered. Descriptive statistics was used for analysis of data. Frequency was shown as percentage. RESULTS: The important suggestion obtained was to use of combination of conventional \& advanced methods to make lectures effective (52\%). Students mentioned that, practical sessions of clinical examination are most interesting (70\%) and that of experimental are least interesting (87\%). It was also observed that interactive classes having bilateral communication (tutorials) were more popular (79\%) amongst the students as compared to lectures. One not to forget is requirement of experienced faculties to teach (80\%).CONLUSION: Demands of relevant modifications in the curriculum of physiology as well as other medical subjects are made time to time. We hope during modifications these issues will be discussed.
\end{abstract}

Key words: Physiology, Feedback, Teaching methods.

\section{Introduction:}

The mainstream of tertiary education has seen a massive transformation over the last few decades. ${ }^{1}$ The goalposts have changed from teaching facts, to helping students to learn how to find relevant information, how to assess it and how to organize disparate information into a cohesive whole and the move towards student centered learning is finding support in the physiological sciences. ${ }^{2-5}$ This triggered a virtual explosion of innovation in teaching/learning strategies and it is becoming increasingly urgent to find ways of evaluating them. ${ }^{6}$ So, there is a need for educational research and on-going evaluation must be considered to be a fundamental part of educational advance. ${ }^{7}$ The simplest measurement of outcome is by examination and several studies have attempted educational evaluation using examination. ${ }^{8-12}$ But currently, the most pragmatic and realistic approach in educational evaluation is to focus on students' perception of their experience with a learning program and this approach has been used in several studies. ${ }^{13-17}$ Present study is also an attempt to evaluate the teaching methods in Physiology by taking students' opinion.

\section{Aim \& objectives:}

To evaluate the different teaching methods practiced in Physiology using students' feedback.

\section{Material \& methods:}

The study was approved by institutional ethical committee.Study was conducted on 200 medical students of $3^{\text {rd }}$ (II/I) \& $5^{\text {th }}$ (II/III) semester. Enrolled students were explained all the details of the study and objectives. Identity of the students was not disclosed. Based on the teaching methods practiced in the department of Physiology, a questionnaire paper was given to the participants to be answered. The questionnaire consisted of questions regarding:
1. Lectures
2. Tutorials
3. Practicals
4. Other related questions

IV. Statistical analysis:

Descriptive statistics was used for analysis of data. Frequency was shown as percentage. 


\section{Results:}

5.1 Lectures: Thirty two per cent students felt the use of PPT with LCD projector is better during lecture because of better visibility and it makes topic interesting \& effective. Whereas $26 \%$ said that the conventional chalk \& board is the better method because it allows time to understand \& register diagrams. And $52 \%$ felt that the use of LCD projector along with chalk \& board depending upon the need of topic is the best method of lectures. No one is in favour of using OHP.

5.2 Group discussions (Tutorials): Seventy nine per cent said that group discussions are very helpful as small group facilitates understanding, queries can be comfortably asked \& it improves rapport with teachers. Whereas $21 \%$ felt that these are not useful because many a times there is repetitions of topics \& not all students come prepared for discussion.

5.3 Practicals: About practicals, for $70 \%$ of students clinical examination is the most interesting session as it is the time they actually learn to examine patient as a doctor. While $87 \%$ student said experimental is the least interesting session as it contains more of a theory \& no practical as such is done. Although they felt, it is the easiest session to understand.

Ninety two per cent students felt that revision practicals are needed because with repetition of practicals they become more skilled as well as understand \& remember things better. Only $7 \%$ felt that revision practicals should be kept only before examinations \& not frequently.Seventy three per cent said that period allotted to the practical sessions should be rearranged depending upon their clinical importance. While $27 \%$ felt that it is not needed.When asked about Physiology as a subject, $43 \%$ said that the subject is difficult \& $57 \%$ felt that the subject is not difficult but is vast \& volatile.Sixty six per cent felt that teaching in Physiology is adequate, $19 \%$ felt that it is inadequate and only $15 \%$ felt that it is overburdened. Seventy eight per cent felt increasing numbers of examinations facilitates learning while $22 \%$ felt that number of examinations does not affect learning. Eighty percent students felt that along with the knowledge of subject, experience of teachers do affect quality of teaching as experienced teachers are skilled to make topic concise, interesting \& easy to understand. While $9 \%$ felt that experience of the teacher does not affect the quality of teaching. $11 \%$ did not give any opinion.

\section{Discussion and conclusion:}

The important suggestion obtained was to use of combination of conventional \& advanced methods to make lectures effective. It was observed that, practical sessions of clinical examination are most interesting and that of experimental are least interesting. So, efforts can be done to make these topics more interesting. It was also observed that interactive classes having bilateral communication (tutorials) were more popular amongst the students as compared to lectures. Similar result was found in study conducted by Chavda $\mathrm{N}$ et al. ${ }^{18}$ This enhances the student's involvement in topic which may affect their performance in examination positively. ${ }^{19}$ One not to forget is requirement of experienced faculties to teach. Demands of relevant modifications in the curriculum of physiology as well as other medical subjects are made time to time. ${ }^{20} \mathrm{We}$ hope during modifications these issues will be discussed. This study is just a small attempt to gather the opinion of students about teaching methods $\&$ whether any changes can be made to improve it. This definitely is not a complete picture. Our study does not intend to judge the existing methods.

\section{Acknowledgements:}

corresponding author likes to thank all students for their participation in the study.

\section{References}

[1]. Laurillard, D. 1993, Re-thinking University Teaching: A Framework for the Effective Use of Educational Technology. London: Routledge

[2]. McCrone J. Wild minds: The dynamics of the neural code. New Scientist. 1997;156:26-30

[3]. Reese AC Implication of results from cognitive science research for medical education. Acad Med 1996 Sep;71(9):988-1001

[4]. Anderson MC, Neely JH Interference and inhibition in memory retrieval Cited in Reese AC Acad Med 1996 Sep;71(9):988-1001

[5]. Regehr G, Norman GR. Issues in cognitive psychology: Implications for professional education.

[6]. Sydille K L. Evaluation of teaching and learning strategies. Med Educ Online (serial online) 2001;6:4

[7]. Van Der Vleuten CPM, Dolmans D.H.J.M,.Scherpbier A.J.J.A. The need for evidence ineducation. Medical Teacher, 2000; 22 (3): 246-250

[8]. Shellhart WC and Oesterle LJ: Assessment of CD-ROM technology on classroom teaching. J Dent Educ 1997;61:817-820

[9]. Login GR, Ransil BJ, Meyer MC et al: Assessment of preclinical problem-based learning versus lecture-based learning. J Dent Educ:1997;61:473-9,

[10]. Bachman MW, Lua MJ, Clay DJ et al: Comparing traditional lecture vs. computer based instruction for oral anatomy. J Dent Educ 1998;62:587-591

[11]. Lindquist TJ, Clancy JMS, Johnson LA et al: Effectiveness of computer-aided partial denture design. J Prosthod 1997;6:122-127 
[12]. Mulligan R, Wood GJ: A controlled evaluation of computer assisted training simulations in geriatric dentistry. J Dent Educ 1993;57:16-24

[13]. Boyd EM, Fales AW. Reflective learning: the key to learning from experience. J Humanistic Psychology.1983;23:99-117.

[14]. Peters A et al. Learner centered approaches in medical education. Academic Medicine 2000; 75: 470-479.

[15]. Schuhbeck M et al.. Long-term Outcomes of the New Pathway Program at Harvard Medical School A Randomized Controlled Trial. European J Dent Edu. 1999; 3(1):35-43.

[16]. Manogue M et al Improving student learning in root canal treatment using self-assessment. Internat Endodontic J. 1999;32(5):397405 .

[17]. Wenzel A, Gotfredsen E. Students' attitudes towards and use of computer-assisted learning in oral radiology over a 10-year period. 1997 Dento-Maxillo-Facial Radiology. 26(2):132-6.

[18]. Second year student's feedback on teaching methodology and evaluation methods in pharmacology. NileshChavda, Preeti Yadav, et al. National Journal of Physiology, Pharmacy and Pharmachology. 2011; 1: 23-31

[19]. Kaufman M, Mann V. Achievements of students in conventional and problem based learning (PBL) curriculum. Adv Health Sci Edu 1999; 4: 245-60.

[20]. Desai M. Changing face of Pharmachology practicals for medical undergraduates. Indian J Pharmachol 2009; 41: 151-2.

\section{Lectures:}

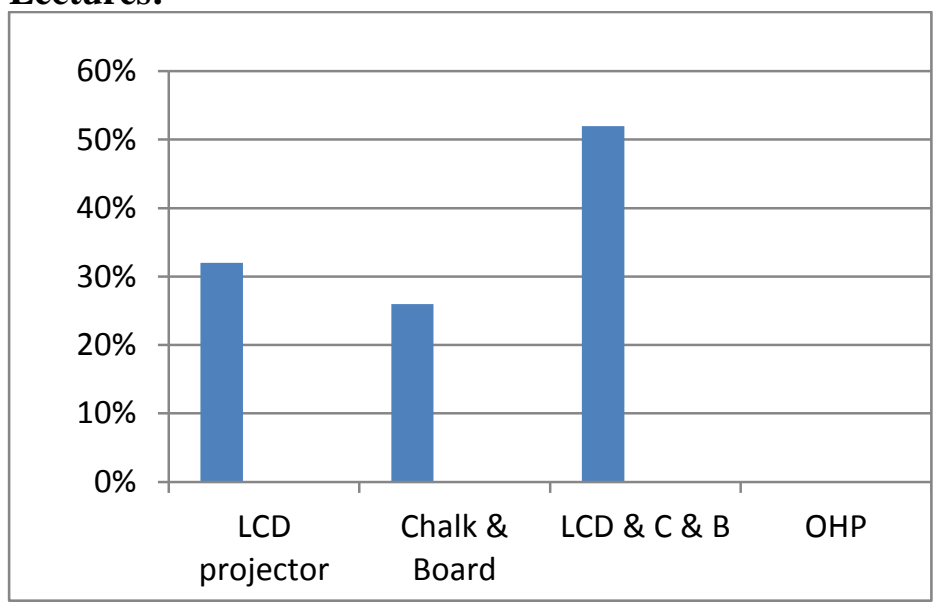

\begin{tabular}{|l|l|}
\hline PPT with LCD Projector & $32 \%$ \\
\hline Chalk \& Board & $26 \%$ \\
\hline OHP & $0 \%$ \\
\hline LCD \& Chalk \& Board & $52 \%$ \\
\hline
\end{tabular}

\section{Lecture Strategy:}

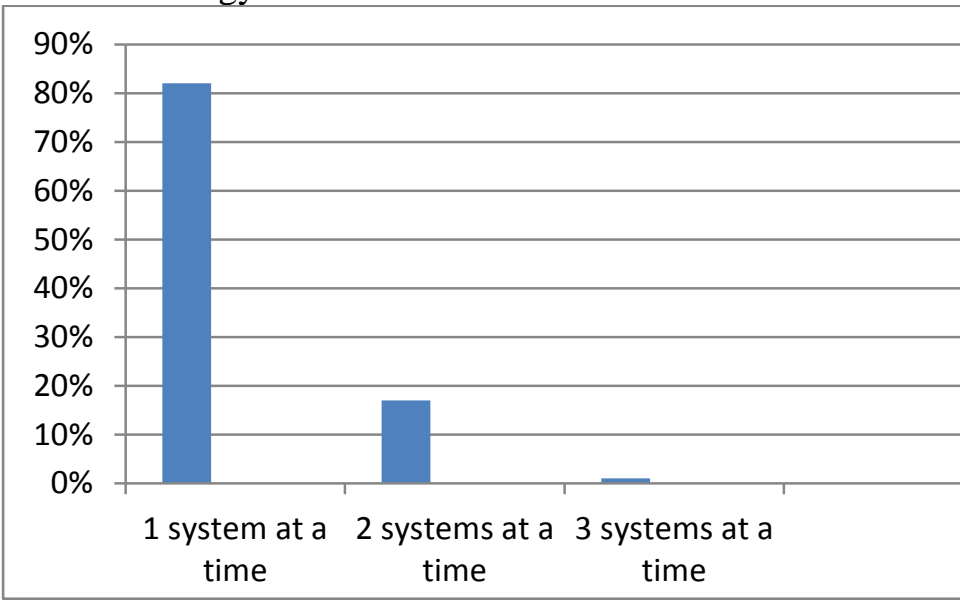

\section{Tutorials}

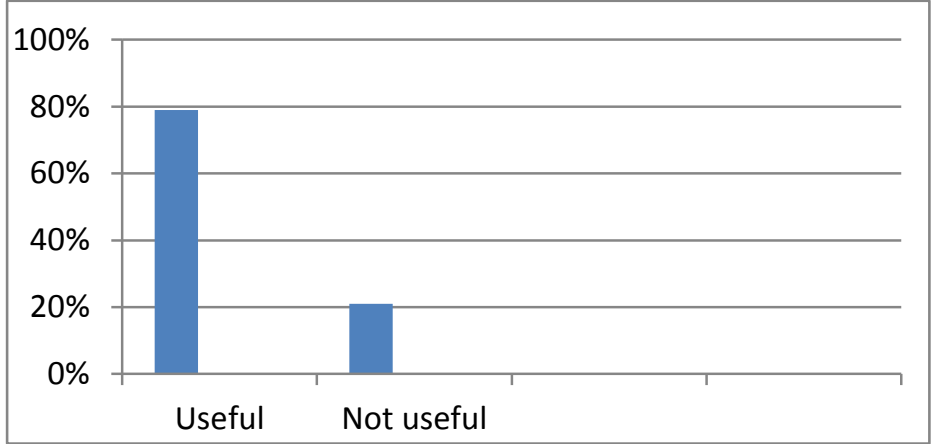

\begin{tabular}{|l|l|}
\hline 1 system at a time & $82 \%$ \\
\hline 2 systems at a time & $17 \%$ \\
\hline 3 systems at a time & $1 \%$ \\
\hline
\end{tabular}




\section{Practicals:}

Most interesting session

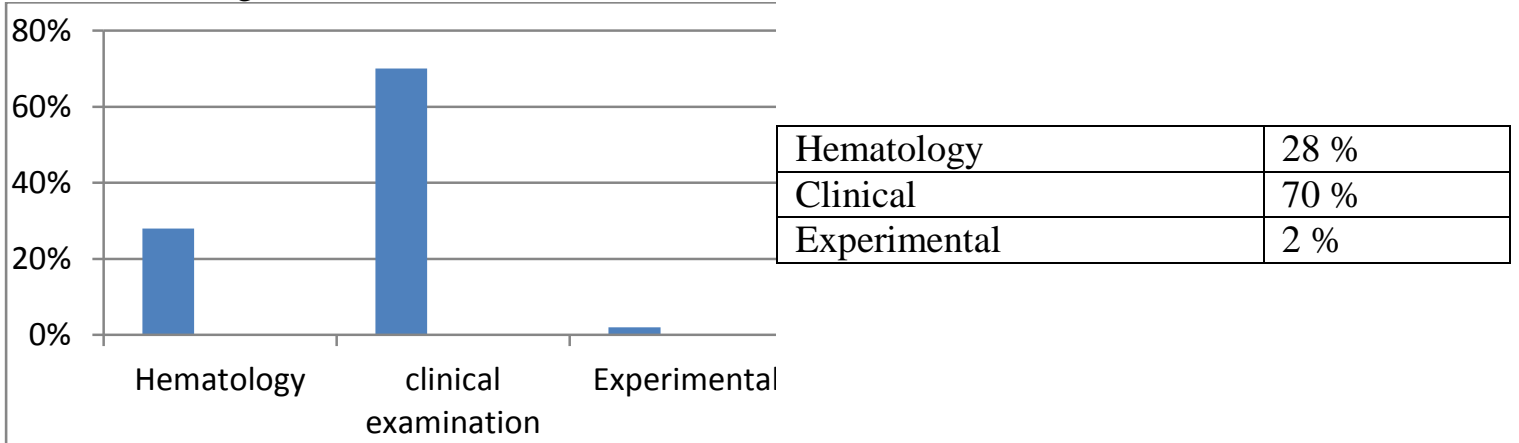

Least interesting session

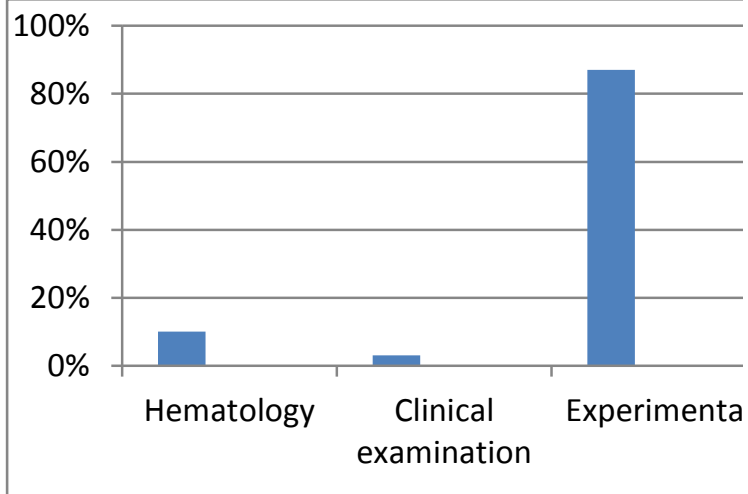

Revision practicals

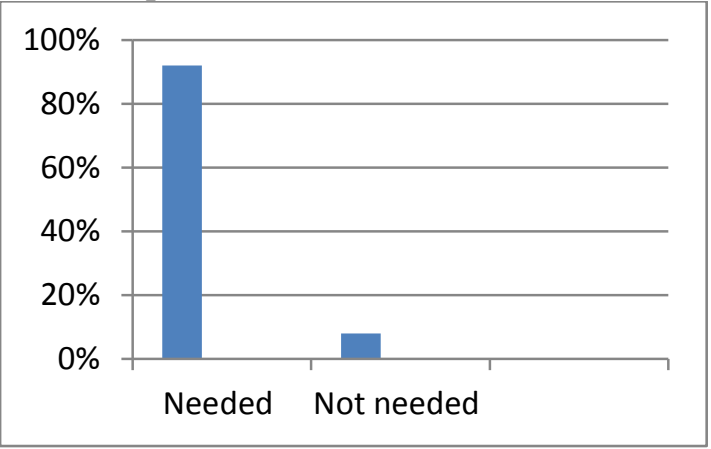

\begin{tabular}{|l|l|}
\hline Hematology & $10 \%$ \\
\hline Clinical & $3 \%$ \\
\hline Experimental & $87 \%$ \\
\hline
\end{tabular}

Reallotment of period for practical sessions:

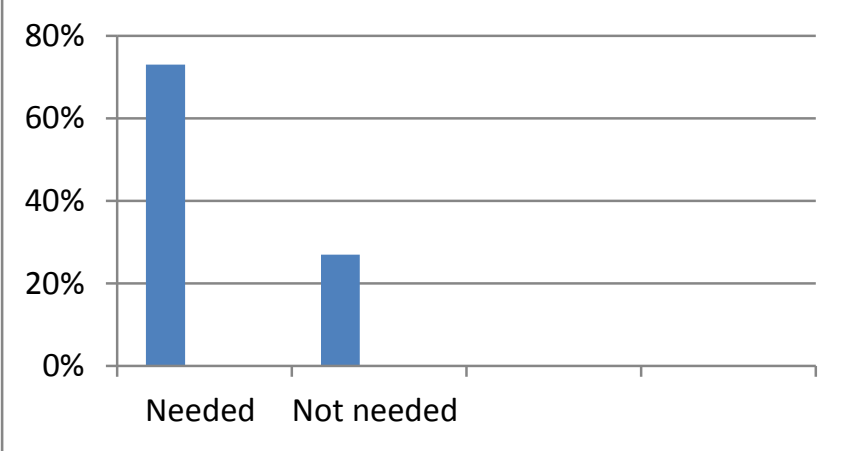

\begin{tabular}{|l|l|}
\hline Needed & $92 \%$ \\
\hline Not needed & $8 \%$ \\
\hline
\end{tabular}

\begin{tabular}{|l|l|}
\hline Needed & $73 \%$ \\
\hline Not needed & $27 \%$ \\
\hline
\end{tabular}


Physiology: As a subject

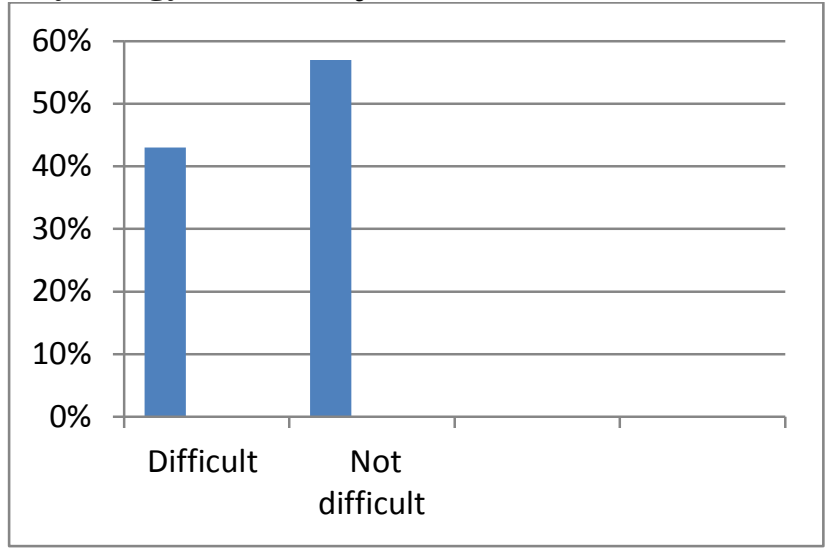

\begin{tabular}{|l|l|}
\hline Difficult & $43 \%$ \\
\hline Not difficult & $57 \%$ \\
\hline
\end{tabular}

Teaching in physiology:

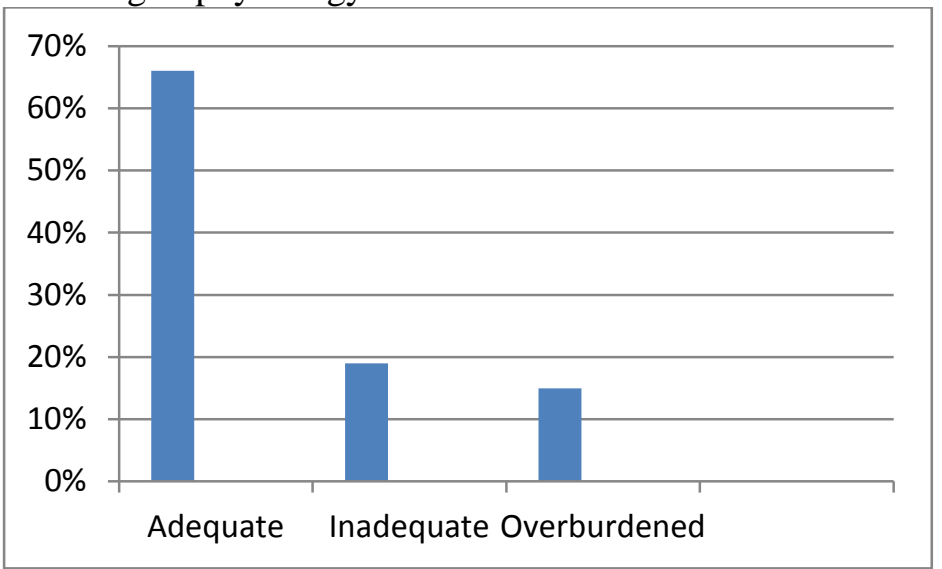

\begin{tabular}{|l|l|}
\hline Adequate & $66 \%$ \\
\hline Inadequate & $19 \%$ \\
\hline Overburdened & $15 \%$ \\
\hline
\end{tabular}

More Number of examinations:

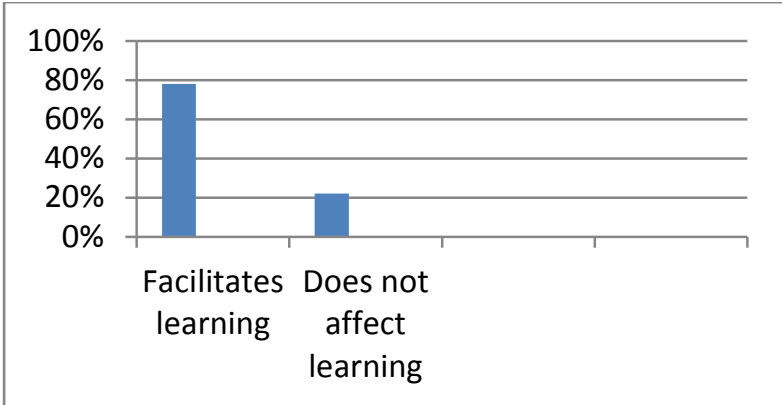

\begin{tabular}{|l|l|}
\hline Facilitates learning & $78 \%$ \\
\hline Does Not affect learning & $22 \%$ \\
\hline
\end{tabular}

Experience of teacher:

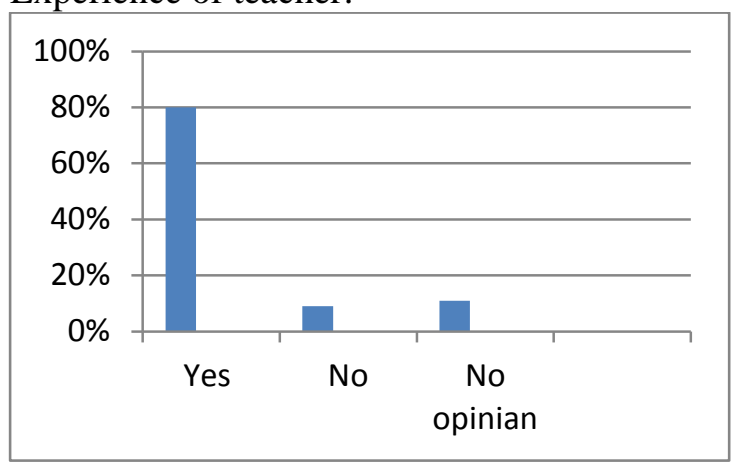

\begin{tabular}{|l|l|}
\hline Yes & $80 \%$ \\
\hline No & $9 \%$ \\
\hline No opinion & $11 \%$ \\
\hline
\end{tabular}

